\title{
Cold Chain Logistics Enterprise Performance Evaluation Based on DEA-AHP and
}

\section{Its Improved Method}

\author{
Wujun Cao, Mengna Yan, Lansheng Zhang \\ Institute of Management Engineering, Zhengzhou University, No. 100 science Avenue, Zhengzhou, China \\ caowujun@zzu.edu.cn,896023218@qq.com,2735908488@qq.com
}

Keywords: Cold Chain Logistics Enterprise, Performance Evaluation, Data Envelopment Analysis, Analytic Hierarchy Process

\begin{abstract}
China's evaluation on the cold chain logistics enterprise performance research starts late, the content of research is not deep enough, which has not formed an evaluation index system and evaluation method of cold chain logistics enterprise performance. Based on the relevant literature and survey analysis, the first of the modern cold chain logistics enterprise performance evaluation index the system was perfect; based on this system, this paper presents an improved evaluation method of DEA-AHP based on cold chain logistics enterprise performance, and finally verifies the
\end{abstract} feasibility of this method by an example.

\section{INTRODUCTION}

With the rapid development of city economy and the improvement of the level of China's cold chain, residents consumption level and consumption capacity increased year by year, in addition, with Australia, the implementation of China ROK FTA, "development as well as the mobile Internet era The Belt and Road" construction of the arrival of the cold chain logistics enterprise got rapid development at the same time, the residents of the fresh product diversification, freshness, put forward higher requirements for safety, the domestic cold chain logistics enterprise is confronted with hitherto unknown opportunities and challenges.

To build a scientific and reasonable performance evaluation index system, choose a suitable method of performance evaluation of enterprises, to seize the opportunity for the cold chain logistics enterprises, is very important to deal with the challenges. At present, the domestic scholars mostly study is to evaluate the performance of the general logistics enterprises, the research on cold chain logistics enterprises are still relatively scarce. The rapid development of the cold chain logistics era, the establishment of performance evaluation system suitable for cold chain logistics enterprises, choose the suitable performance evaluation method of the enterprise, is the modern cold chain logistics enterprises eager to solve the problem.

\section{CONSTRUCTING INDEX}

In the research of China's cold chain logistics performance evaluation, the enterprise management ability, liquidity and profitability index of three one class as the starting point of research (Haolin Tong, 2014). The performance evaluation of cold chain logistics enterprises should mainly from the financial performance indicators, operational performance indicators, service performance indicators and human performance indicators to build four indicators system(Jing Zhou ,Jian Sun, 2015). In the study of cold chain logistics performance evaluation of agricultural products based on Data Envelopment Analysis (DEA), selecting evaluation indicators from four aspects: external environment, internal process, overall benefit and risk assessment (Weishu Xu, Xiangyu Fan, 2015). Enterprise performance evaluation of cold chain logistics of agricultural products, cold chain logistics enterprise performance evaluation index of agricultural products mainly includes six aspects, namely: financial management, logistics system, customers satisfaction, environmental protection, information sharing and innovation and development ability (Yuping Huang, 2016).

This article from the financial, logistics management, informationization level, customer service and development potential of the five aspects of selection of cold chain logistics enterprise performance evaluation index.

\subsection{Financial Performance Indicators}

Financial performance indicators reflect the operating status of cold chain logistics enterprises at a certain stage, through the total assets profitability, capital turnover, asset liability ratio and cost profit margins.

(1) profit rate of total assets

The total assets profit margin is the ratio of the cold chain logistics enterprise income in a period of time in the business gross profit and average total assets, in order to reflect the company's overall business conditions.

(2) capital turnover rate

The capital turnover rate is the ratio of cold chain logistics enterprises in a period of time the net operating income and average total assets, business quality and resource utilization efficiency is a comprehensive reflection of the enterprise index.

(3) asset liability ratio

The asset liability ratio is used to evaluate the degree of debt and the degree of operational risk of cold chain logistics enterprises. It is the ratio of total liabilities to total assets in a period of operation.

(4) cost profit margin 
Cost profit rate is the ratio of the total gross profit of the cold chain logistics enterprise income in a period of time and operating cost, the index shows that the cost can be paid one yuan per profit reflects the operating results of an enterprise.

\subsection{Logistics Operation Performance Indicators}

Logistics operation performance index to reflect the cold chain logistics enterprises in the main business activities: transportation, warehousing activities in the performance level. The indexes of the cold storage utilization rate, inventory turnover rate, the rate of refrigerated transport and damage rate to reflect the use of refrigerated trucks.

(1) utilization ratio of cold storage

As an important infrastructure of cold chain logistics enterprises, the use efficiency of cold storage has a great impact on the performance level of cold chain logistics enterprises.

(2) inventory turnover

For the cold chain logistics enterprises, the inventory turnover rate is the ratio of a period of time in cold storage time of fresh products with the shelf life of the product.

(3) utilization rate of refrigerated vehicles

Refrigerated truck utilization rate is a reflection of the cold chain logistics enterprise on one index of fresh products transportation management tool, is a period of time the average load of refrigerated trucks and refrigerated vehicles approved volume ratio.

(4) damage rate of refrigerated transportation

The damage rate of refrigerated transportation is the management level index reflecting the quality of fresh products operated by cold chain logistics enterprises. It is the ratio of the total value of damaged products to the total value of transported products during refrigerated transportation in a period of time.

\subsection{Informatization Level Performance Indicators}

The arrival of information age makes the logistics information system has developed rapidly, the use of advanced logistics system, convenient for the cold chain logistics enterprises to improve the level of performance is very important. The indexes of the advanced information processing timeliness, accuracy of information and information system.

(1) the rate of timely information processing

The timeliness of information processing is used to reflect the timeliness of dealing with internal information of cold chain logistics enterprises. It is the ratio of the number of timely processing of information and the total number of information processing.

(2) the accuracy of information

The accuracy of information is the index of the information transmission between the departments of cold chain logistics enterprises. It is the ratio of the correct transfer of information and the total number of information transfer.

(3) the advanced nature of information system

The advanced nature of information system is the index that reflects the importance of cold chain logistics enterprises to update the equipment of enterprise information, and the ratio of the cost of putting information system into the total sales revenue in a certain period of time.

\subsection{Customer Service Performance Indicators}

Customer service quality has a direct impact on the performance level of cold chain logistics enterprises, which is reflected by customer satisfaction, on-time delivery rate and customer retention rate.

(1) customer satisfaction

Customer satisfaction is a measure of customer satisfaction with the product quality and after-sales service provided by cold chain logistics enterprises. It is the ratio of the number of customer complaints and the total number of orders in a certain period.

(2) the on-time delivery rate

Rate of delivery on time delivery reliability can be used to measure the cold chain logistics enterprise of fresh products, is a certain period of time delivery times and the ratio of the total number of delivery period.

(3) customer retention rate

Customer retention rate is maintained in the cold chain logistics enterprises reflect the customer loyalty and the degree of cold chain logistics enterprise market index is the ratio of the number of customers and enterprises in the year $\mathrm{K}$ the first year of the number of customers.

\subsection{Development Potential Performance Indicators}

Assessment of the potential for development of cold chain logistics enterprises, which can help companies identify their cold chain in the fierce market competition, better management of the daily management of the enterprise, is conducive to the long-term development of enterprises. The index by market share, marketing ability and employee training rate to reflect.

(1) market share

Market share is the evaluation of the main business of cold chain logistics enterprise share index in the market, is the ratio of a certain period of cold chain logistics enterprises and the turnover period of cold chain logistics market turnover.

(2) market development ability

Market development ability is the development ability of new customers, which is the ratio of the number of new customers and the total amount of customers in a certain period.

(3) the rate of employee training

Employee training rate is used to reflect employee skills, is the number of training staff in a certain period and the total number of employees during the period.

\section{PROBLEM DESCRIPTION}

\subsection{The Original Application Steps}

By reading the relevant literature, we can see that the majority of scholars have been aware of the DEA, AHP based on enterprise performance evaluation. The specific steps are as follows(Jiazhen Huo, Min Zhou, 2009):

(1) pairwise comparisons of DEA

In accordance with the principle of DEA model and evaluation method, to analyze the effectiveness of any $n$ 
decision-making unit of decision making units $\mathrm{A}$ and $\mathrm{B}$, ignoring the other decision making unit. With $\mathrm{E}_{\mathrm{AA}}, \mathrm{E}_{\mathrm{AB}}$, said the optimal objective function of linear programming problems LP1 and LP2 values, that is:

LP1

$$
\begin{gathered}
\mathrm{E}_{\mathrm{AA}}=\max \sum_{\mathrm{r}=1}^{\mathrm{s}} \mathrm{u}_{\mathrm{r}} \mathrm{y}_{\mathrm{rA}} \\
\text { s.t. }\left\{\begin{array}{l}
\sum_{\mathrm{I}=1}^{\mathrm{m}} \mathrm{v}_{\mathrm{i}} \mathrm{x}_{\mathrm{iA}}=1 \\
\sum_{\mathrm{r}=1}^{\mathrm{s}} \mathrm{u}_{\mathrm{r}} \mathrm{y}_{\mathrm{rA}} \leq 1 \\
\sum_{\mathrm{r}=1}^{\mathrm{s}} \mathrm{u}_{\mathrm{r}} \mathrm{y}_{\mathrm{rB}}-\sum_{\mathrm{I}=1}^{\mathrm{m}} \mathrm{v}_{\mathrm{i}} \mathrm{x}_{\mathrm{iB}} \leq 0 \\
\mathrm{u}_{\mathrm{r}}, \mathrm{v}_{\mathrm{i}} \geq 0 \\
r=1,2, \cdots, s ; \mathrm{i}=1,2, \cdots, m
\end{array}\right.
\end{gathered}
$$

$$
\mathrm{E}_{\mathrm{AB}}=\max \sum_{\mathrm{r}=1}^{\mathrm{s}} \mathrm{u}_{\mathrm{r}} \mathrm{y}_{\mathrm{rB}}
$$

LP2

$$
\text { s.t. }\left\{\begin{array}{l}
\sum_{\mathrm{i}=1}^{\mathrm{m}} \mathrm{v}_{\mathrm{i}} \mathrm{x}_{\mathrm{iB}}=1 \\
\sum_{\mathrm{r}=1}^{\mathrm{s}=1} \mathrm{u}_{\mathrm{r}} \mathrm{y}_{\mathrm{rB}} \leq 1 \\
\sum_{\substack{\mathrm{r}=1 \\
\mathrm{u}_{\mathrm{r}}, \mathrm{v}_{\mathrm{i}} \geq 0 \\
r=1,2, \cdots, s ; i=1,2, \cdots, m}} \mathrm{u}_{\mathrm{r}} \mathrm{y}_{\mathrm{rA}}-\mathrm{E}_{\mathrm{AA}} \sum_{\mathrm{i}=1}^{\mathrm{m}} \mathrm{v}_{\mathrm{i}} \mathrm{x}_{\mathrm{iA}} \leq 0
\end{array}\right.
$$

Similarly, $\mathrm{E}_{\mathrm{BB}}, \mathrm{E}_{\mathrm{BA}}$. can be calculated.

(2) constructing AHP judgment matrix

Let Apq represent the elements of row P, column Q in the judgment matrix:

$$
a_{p q}=\frac{E_{p P}+E_{p q}}{E_{q q}+E_{q p}}
$$

Which $a_{p p}=1, a_{p q}=1 / a_{q p}$

\section{(3) AHP sort}

The two step calculated judgment matrix $\mathrm{A}=$ $\left[a_{p q}\right]_{\mathrm{n} \times \mathrm{n}}$ and $\mathrm{a}_{\mathrm{pq}}$ substitution into eigenvalue problem $\operatorname{det}(\mathrm{A}) W=\lambda_{\max } W$.Solving the lambda $\max$ and its corresponding eigenvectors $\boldsymbol{w}=\left(w_{1}, w_{2}, \ldots, w_{n}\right)^{T}$, Then the $i$ component $w_{i}$ reflects the relative importance of the $i$ decision unit.

\subsection{Example}

Because of the cold chain logistics enterprise is a type of logistics enterprises, in the premise of it has the basic characteristics of the logistics enterprise, but also has its own unique characteristics, it is more concerned with the quality of fresh products, the efficiency of transportation, warehousing and other aspects, therefore, based on the logistics enterprise system focuses on analysis of transportation the efficiency, quality, inventory of goods damage rate, customer service and other aspects of the index, which launched the cold chain logistics enterprise performance evaluation.

The first step to construct the input/output system.

\begin{tabular}{|c|c|c|c|c|c|c|c|c|}
\hline Index & $\mathrm{DMU}_{1}$ & $\mathrm{DMU}_{2}$ & $\mathrm{DMU}_{3}$ & $\mathrm{DMU}_{4}$ & $\mathrm{DMU}_{5}$ & $\mathrm{DMU}_{6}$ & $\mathrm{DMU}_{7}$ & $\mathrm{DMU}_{8}$ \\
\hline Net worth $\%(y)$ & 20.00 & 17.40 & 11.80 & 9.00 & 9.40 & 10.60 & 13.60 & 8.00 \\
\hline Rate of Return on total Assets/\%(y) & 15.00 & 7.35 & 12.60 & 11.85 & 14.25 & 13.50 & 9.60 & 60.00 \\
\hline Turnover rate of funds $/ \%(y)$ & 25.00 & 16.00 & 23.00 & 12.25 & 18.75 & 21.25 & 14.50 & 10.00 \\
\hline $\begin{array}{c}\text { Total warehousing cost / annual reserve } \\
\text { fund } / 10^{-6}(x)\end{array}$ & 1.30 & 2.60 & 2.34 & 2.86 & 1.69 & 2.47 & 1.95 & 3.25 \\
\hline Annual warehousing cost / budget $/ \%(x)$ & 5.00 & 7.50 & 10.00 & 9.00 & 8.50 & 6.00 & 6.50 & 12.50 \\
\hline The amount of inventory / budget/\%( $x)$ & 5.00 & 9.00 & 8.50 & 11.00 & 6.50 & 10.00 & 7.50 & 12.50 \\
\hline $\begin{array}{l}\text { Stock funds accounted for a } \\
\text { percentage } / \%(x)\end{array}$ & 2.50 & 5.25 & 3.75 & 4.75 & 3.50 & 5.75 & 5.00 & 6.25 \\
\hline $\begin{array}{l}\text { The percentage of freight accounted for } \\
\text { the value of the goods/ } \%(x)\end{array}$ & 1.70 & 3.40 & 3.74 & 3.06 & 2.72 & 2.21 & 3.23 & 4.25 \\
\hline Freight / yuan per ton kilometer $(x)$ & 0.23 & 0.39 & 0.32 & 0.28 & 0.48 & 0.44 & 0.37 & 0.58 \\
\hline Damage rate of transport articles/\%o $(x)$ & 0.10 & 0.12 & 0.16 & 0.44 & 0.14 & 0.24 & 0.28 & 0.50 \\
\hline Transportation accidents/\%o $(x)$ & 0.30 & 0.39 & 0.36 & 0.42 & 0.45 & 0.54 & 0.60 & 0.75 \\
\hline Item error rate/\%o $(x)$ & 0.10 & 0.13 & 0.16 & 0.15 & 0.11 & 0.23 & 0.18 & 0.25 \\
\hline $\begin{array}{l}\text { Utilization ratio of transport capacity/\% } \\
(y)\end{array}$ & 95.00 & 65.55 & 76.00 & 63.65 & 62.70 & 66.50 & 71.25 & 38.00 \\
\hline Efficiency of loading $/ \%(y)$ & 85.00 & 43.35 & 49.30 & 46.65 & 76.50 & 70.55 & 65.45 & 34.00 \\
\hline Transportation labor productivity/\%(y) & 90.00 & 40.50 & 51.30 & 44.10 & 72.00 & 54.90 & 61.20 & 36.00 \\
\hline Deferred delivery rate/\%o $(x)$ & 5.00 & 7.50 & 9.00 & 9.50 & 7.00 & 6.00 & 8.50 & 12.50 \\
\hline Inventory damage rate/\%o $(x)$ & 0.010 & 0.015 & 0.024 & 0.012 & 0.017 & 0.015 & 0.018 & 0.025 \\
\hline The capacity utilization rate $/ \%(y)$ & 60.00 & 53.40 & 40.80 & 47.40 & 45.00 & 36.00 & 28.80 & 24.00 \\
\hline $\begin{array}{l}\text { The utilization rate of storage } \\
\text { equipment } / \%(y)\end{array}$ & 65.00 & 58.50 & 57.85 & 38.35 & 31.85 & 59.15 & 55.90 & 26.00 \\
\hline Product information availability $/ \%(y)$ & 97.00 & 89.24 & 80.51 & 75.66 & 64.02 & 50.44 & 53.35 & 38.80 \\
\hline market share $/ \%(y)$ & 5.00 & 3.90 & 3.45 & 4.30 & 3.00 & 4.75 & 2.80 & 2.00 \\
\hline Order tracking capability $/ \%(y)$ & 95.00 & 63.65 & 84.55 & 56.05 & 60.80 & 75.05 & 45.60 & 38.00 \\
\hline Order fulfillment accuracy $/ \%(y)$ & 99.00 & 76.23 & 57.42 & 89.10 & 49.50 & 69.30 & 84.15 & 39.60 \\
\hline
\end{tabular}
On the basis of the five kinds of performance evaluation index is constructed for the input/output system. The smaller indicators as input indicators, the bigger indicators as output indicators. Eight to evaluate the original evaluation decision unit data(Dequan Yang, Jinying Pei, 2012)shown in table 1. The input index (expressed by x. The output index by y).

Table 1: Original evaluation data

The product quality, the efficiency of transportation, warehousing and other aspects, therefore, based on the 
logistics enterprise system focuses on analysis of the transportation efficiency, quality, inventory of goods damage rate, customer service and other aspects of the index, which launched the cold chain logistics enterprise performance evaluation.

The second step conversion index. In order to enable comparability between indicators, the need for the corresponding input and output index normalized conversion formula is as follows:

$$
\left\{\begin{array}{c}
\mathrm{x}_{\mathrm{ij}}^{\prime}=\frac{\mathrm{x}_{\mathrm{ij}}}{\sum_{\mathrm{j}=1}^{\mathrm{n}} \mathrm{x}_{\mathrm{ij}}} \\
\mathrm{y}_{\mathrm{rj}}^{\prime}=\frac{\mathrm{y}_{\mathrm{rj}}}{\sum_{\mathrm{j}=1}^{\mathrm{n}} \mathrm{y}_{\mathrm{rj}}} \\
i=1,2, \cdots, m ; r=1,2, \cdots, s
\end{array}\right.
$$

$\mathrm{x}_{\mathrm{ij}}$ represents the $\mathrm{i}$ input index of the first $\mathrm{j}$ decision making unit, $\mathrm{y}_{\mathrm{ij}}$ represents the $\mathrm{R}$ output index of the first $\mathrm{j}$ decision making unit.

In the third step, the judgment matrix is constructed by using data envelopment analysis method. The two decision units are compared, and the validity values are calculated.

The fourth step, using the eigenvalue equations of feature vector eigenvalues and corresponding.

By calculate, the solution is $\lambda_{\max }=8.1718$; The corresponding eigenvectors are: $\boldsymbol{w}=(1.4869,1.0131$, $1.0313,1.0088,1.0290,1.0187,1.0335,0.6887)^{T}$.

The fifth step is to check the consistency of the judgment matrix. Combined with numerical, fourth step calculated by formula, conformance testing, solution $C R=0.0172<0.10$,Said the consistency of the judgment matrix is satisfied at this time. Through the consistency test, obtains the AHP comprehensive ranking results are shown in Table 2.

Table 2: The final results.

\begin{tabular}{|c|c|c|}
\hline Decision package & Forder & Sort \\
\hline DMU $_{1}$ & 1.8485 & 1 \\
\hline DMU $_{2}$ & 1.0333 & 2 \\
\hline DMU $_{3}$ & 1.0310 & 3 \\
\hline DMU $_{4}$ & 1.0291 & 4 \\
\hline DMU $_{5}$ & 1.0188 & 5 \\
\hline DMU $_{6}$ & 1.0132 & 6 \\
\hline DMU $_{7}$ & 1.0088 & 7 \\
\hline DMU $_{8}$ & 0.6887 & 8 \\
\hline
\end{tabular}

We can see from table 2, the decision unit 1 of the highest level of performance, the performance of the lowest level of decision unit 8.

\subsection{Analysis of The Original Features}

Although the above method can be used for various enterprises to make the performance evaluation, but the method still needs to be improved, it can help decision makers make better decisions for the enterprise itself does not help, in addition, data envelopment analysis for cold chain logistics enterprise performance evaluation of the 1 efficiency values and AHP method only constructs the judgment matrix of the values and which exist in real life some fuzzy measures do not meet, thus easily lead to wrong decisions.

\section{IMPROVED METHOD}

Combining the advantages of DEA and fuzzy analytic hierarchy process (AHP), the paper evaluates the performance of cold chain logistics enterprises by combining the two methods:

1) Constructing the performance evaluation index system of cold chain logistics enterprises;

2) Constructing input / output system;

3) Based on the various indicators and the level of total order and the consistency check of the fuzzy analytic hierarchy process;

4) The analysis method to calculate the efficiency evaluation of each DMU using super efficiency data envelopment;

5) Using the results of 3) and 4) to calculate the overall efficiency value, in order to get the order of each enterprise performance.

\subsection{Examples}

The first step, five types of evaluation index can be divided into four categories in order to build a more specific cold chain logistics enterprise performance evaluation index system, namely: Transport index $\left(B_{1}\right)$, storage index $\left(B_{2}\right)$, service index $\left(B_{3}\right)$ and potential index $\left(\mathrm{B}_{4}\right)$.

The second step to construct the input / output system. The smaller the better indicators as input indicators, the bigger the better indicators as output indicators. Eight to evaluate the original evaluation decision unit data are shown in Table 1 . (the input index $\mathrm{x}$, output index denoted by y.)

The third step is to use fuzzy analytic hierarchy process (AHP) to rank all the indexes and check their consistency:

1) Construct the fuzzy complementary judgment matrix (take four experts as an example).

The fuzzy complementary judgement matrix given by expert Jia is as follows.

\begin{tabular}{|l|l|l|l|l|}
$\mathrm{A}_{1}$ & $\mathrm{~B}_{1}$ & $\mathrm{~B}_{2}$ & $\mathrm{~B}_{3}$ & $\mathrm{~B}_{4}$ \\
\hline $\mathrm{B}_{1}$ & 0.5 & 0.6 & 0.5 & 0.4 \\
\hline $\mathrm{B}_{2}$ & 0.4 & 0.5 & 0.4 & 0.3 \\
$\mathrm{~B}_{3}$ & 0.5 & 0.6 & 0.5 & 0.4 \\
$\mathrm{~B}_{4}$ & 0.6 & 0.7 & 0.6 & 0.5 \\
\hline
\end{tabular}

According to formula of weight vector $\boldsymbol{W}_{\mathbf{1}}$ $=(0.250,0.217,0.250,0.283)^{T}$. Then, the characteristic matrix of $A_{1}$ is calculated by formula.

$W_{1}^{*}=\left(\begin{array}{cccc}0.500 & 0.535 & 0.500 & 0.469 \\ 0.465 & 0.500 & 0.465 & 0.434 \\ 0.500 & 0.535 & 0.500 & 0.469 \\ 0.531 & 0.566 & 0.531 & 0.500\end{array}\right)$

By calculating, we see the compatibility index $\mathrm{I}\left(\mathrm{A}_{1}, \mathrm{~W}_{1}{ }^{*}\right)=0.050<0.1$, the weight vector $\mathrm{W}_{1}$ is 
reasonable. The fuzzy complementary judgement matrix $\mathrm{A}_{1}$ has satisfactory consistency.

The fuzzy complementary judgement matrix given by expert $\mathrm{Yi}$ is as follows.

\begin{tabular}{|l|l|l|l|l|}
$\mathrm{A}_{2}$ & $\mathrm{~B}_{1}$ & $\mathrm{~B}_{2}$ & $\mathrm{~B}_{3}$ & $\mathrm{~B}_{4}$ \\
\hline $\mathrm{B}_{1}$ & 0.5 & 0.7 & 0.6 & 0.5 \\
\hline $\mathrm{B}_{2}$ & 0.3 & 0.5 & 0.4 & 0.3 \\
$\mathrm{~B}_{3}$ & 0.4 & 0.6 & 0.5 & 0.4 \\
$\mathrm{~B}_{4}$ & 0.5 & 0.7 & 0.6 & 0.5 \\
\hline
\end{tabular}

According to the formula of weight vector $\boldsymbol{W}_{2}$ $=(0.275,0.208,0.242,0.275)^{T}$. So the characteristic matrix of $\mathrm{A}_{2}$ is calculated by formula.

$W_{2}^{*}=\left(\begin{array}{llll}0.500 & 0.569 & 0.532 & 0.500 \\ 0.431 & 0.500 & 0.462 & 0.431 \\ 0.568 & 0.538 & 0.500 & 0.468 \\ 0.500 & 0.569 & 0.532 & 0.500\end{array}\right)$

The compatibility index $\mathrm{I}\left(\mathrm{A}_{2}, \mathrm{~W}_{2}^{*}\right)=0.058<0.1$, the weight vector $W_{2}$ is reasonable. The fuzzy complementary judgement matrix $A_{2}$ has satisfactory consistency.

The fuzzy complementary judgment matrix given by expert Bing is as follows.

\begin{tabular}{c|cccc}
$\mathrm{A}_{3}$ & $\mathrm{~B}_{1}$ & $\mathrm{~B}_{2}$ & $\mathrm{~B}_{3}$ & $\mathrm{~B}_{4}$ \\
\hline $\mathrm{B}_{1}$ & 0.5 & 0.8 & 0.5 & 0.4 \\
$\mathrm{~B}_{2}$ & 0.2 & 0.5 & 0.3 & 0.3 \\
$\mathrm{~B}_{3}$ & 0.5 & 0.7 & 0.5 & 0.4 \\
$\mathrm{~B}_{4}$ & 0.6 & 0.7 & 0.6 & 0.5
\end{tabular}

According to the formula of weight vector $W_{3}$ $=(0.267,0.192,0.258,0.283)^{T}$, The formula to calculate the characteristic matrix for $\mathrm{A}_{3}$ is as follows.

$W_{3}^{*}=\left(\begin{array}{llll}0.500 & 0.582 & 0.509 & 0.486 \\ 0.418 & 0.500 & 0.427 & 0.404 \\ 0.491 & 0.573 & 0.500 & 0.477 \\ 0.515 & 0.596 & 0.523 & 0.500\end{array}\right)$

The compatibility index $\mathrm{I}\left(\mathrm{A}_{3}, \mathrm{~W}_{3}^{*}\right)=0.059<0.1$, So the weight vector $W_{3}$ is reasonable. The consistency of judgment matrix $\mathrm{A}_{3}$ has satisfactory consistency.

The fuzzy complementary judgment matrix given by expert Ding is as follows.

\begin{tabular}{l|l|l|l|l}
$\mathrm{A}_{4}$ & $\mathrm{~B}_{1}$ & $\mathrm{~B}_{2}$ & $\mathrm{~B}_{3}$ & $\mathrm{~B}_{4}$ \\
\hline $\mathrm{B}_{1}$ & 0.5 & 0.7 & 0.5 & 0.4 \\
$\mathrm{~B}_{2}$ & 0.3 & 0.5 & 0.4 & 0.3 \\
$\mathrm{~B}_{3}$ & 0.5 & 0.6 & 0.5 & 0.4 \\
$\mathrm{~B}_{4}$ & 0.6 & 0.6 & 0.7 & 0.5 \\
\hline
\end{tabular}

According to the formula of weight vector $\boldsymbol{W}_{\mathbf{4}}$ $=(0.258,0.208,0.250,0.283)^{T}$. Then, the characteristic matrix of $\mathrm{A}_{4}$ is calculated by formula.

$$
W_{4}^{*}=\left(\begin{array}{llll}
0.500 & 0.554 & 0.508 & 0.477 \\
0.446 & 0.500 & 0.454 & 0.424 \\
0.492 & 0.546 & 0.500 & 0.469 \\
0.523 & 0.576 & 0.531 & 0.500
\end{array}\right)
$$

The compatibility index $\mathrm{I}\left(\mathrm{A}_{4}, \mathrm{~W}_{4}^{*}\right)=0.056<$ 0.1 .The weight vector of $W_{4}$ is reasonable and consistent judgment matrix $\mathrm{A}_{4}$ with fuzzy complementary.

To judge the satisfactory consistency between the test matrix four compatibility fuzzy complementary, the four is the average of the weight vector, then the weight of each index value can be expressed as: $W=(0.263,0.206,0.250,0.281)^{T}$.

Step 4, using super efficiency data envelopment analysis method to calculate the efficiency evaluation of each DMU. The equations of the formula to calculate the relative efficiency of each enterprise layer of index value, the calculation results shown in Table 3.

Table 3: Calculation results of super efficiency data envelopment analysis

\begin{tabular}{|c|c|c|c|c|}
\hline DMU & Transport & Store & Serve & $\begin{array}{c}\text { Development } \\
\text { potential }\end{array}$ \\
\hline $\mathrm{DMU}_{2}$ & 0.7500 & 0.6769 & 0.6133 & 0.5118 \\
\hline $\mathrm{DMU}_{3}$ & 0.5894 & 0.5933 & 0.6640 & 0.6133 \\
\hline $\mathrm{DMU}_{4}$ & 0.5586 & 0.6333 & 0.7500 & 0.7167 \\
\hline $\mathrm{DMU}_{5}$ & 0.6429 & 0.8182 & 0.6250 & 0.6667 \\
\hline $\mathrm{DMU}_{6}$ & 0.6385 & 0.5267 & 1.5000 & 0.4523 \\
\hline $\mathrm{DMU}_{7}$ & 0.5346 & 0.8000 & 0.3235 & 0.4857 \\
\hline $\mathrm{DMU}_{8}$ & 0.1600 & 0.1600 & 0.1600 & 1.6000 \\
\hline
\end{tabular}

The fifth step, combined with the results of third steps and fourth steps, calculates the total efficiency values using the formula, and sort them, as shown in Table 5. 
Table5 Overall efficiency value

\begin{tabular}{|c|c|c|c|c|c|c|c|c|c|}
\hline Index & $\begin{array}{c}\text { Index } \\
\text { weight }\end{array}$ & $\mathrm{DMU}_{1}$ & $\mathrm{DMU}_{5}$ & $\mathrm{DMU}_{2}$ & $\mathrm{DMU}_{7}$ & $\mathrm{DMU}_{4}$ & $\mathrm{DMU}_{6}$ & $\mathrm{DMU}_{3}$ & $\mathrm{DMU}_{8}$ \\
\hline Transport & 0.2630 & 1.0000 & 0.6429 & 0.7500 & 0.5346 & 0.5586 & 0.6385 & 0.5894 & 0.1600 \\
\hline Store & 0.2060 & 1.0000 & 0.8182 & 0.6769 & 0.8000 & 0.6333 & 0.5267 & 0.5933 & 0.1600 \\
\hline Serve & 0.2500 & 2.3047 & 0.6250 & 0.6133 & 0.3235 & 0.7500 & 1.5000 & 0.6640 & 0.1600 \\
\hline $\begin{array}{c}\text { Developme } \\
\text { nt potential }\end{array}$ & 0.2810 & 2.1800 & 0.6667 & 0.5118 & 0.4857 & 0.7167 & 0.4523 & 0.6133 & 1.6000 \\
\hline $\begin{array}{c}\text { Overall } \\
\text { efficiency } \\
\text { value }\end{array}$ & $\sigma_{j}$ & 1.2329 & 0.7330 & 0.6807 & 0.6741 & 0.6429 & 0.6303 & 0.6021 & 0.2503 \\
$=\sum_{i=1}^{4} h_{i j} W_{i}$ & & & & & & & & & \\
\hline \multicolumn{2}{|c|}{ sequencing } & 1 & 2 & 3 & 4 & 5 & 6 & 7 & 8 \\
\hline
\end{tabular}

Table 5 shows the decision unit 1, the highest level of performance, the performance of the lowest level of decision unit 8 , and according to the calculated results, clear the weight factors in the enterprise, to enable enterprises to clearly recognize their own shortcomings existing in the development, to take targeted measures to improve the competitiveness of enterprises.

\subsection{Results Comparison}

With the improved method and the original method of the advantages of the same, also do not have the characteristics of the original method has: in the process of calculation considering the preference of decisionmaker, overcome the data envelopment analysis to value of cold chain logistics enterprise performance evaluation of the 1 defects on the efficiency, but also avoids the hierarchy judgment matrix analysis structure is not accurate enough to make the wrong decision, in addition, the application steps of the adjustment can make the cold chain logistics enterprise performance evaluation by the evaluation results in aware of their shortcomings, so as to make targeted improvements; in addition, compared with the original method, the improved method. In the calculation of more It is easy to add and improve work efficiency.

\section{CONCLUSIONS}

Based on the analysis of the performance evaluation results of cold chain logistics enterprises, in order to improve the performance level of modern cold chain logistics enterprises, this paper puts forward the following suggestions:

1) The cold chain logistics enterprise must introduce advanced cold chain technology and equipment, can provide cold chain logistics services quality for customers. But for now, China's cold chain logistics enterprises, cold chain technology is backward, cold storage, refrigerated trucks and other infrastructure is the main factor restricting its rapid development in recent years., the state issued a series of encouraging cold chain logistics enterprises bigger and stronger preferential policies in such favorable conditions, cold chain logistics enterprises should seize the opportunity to increase the cold chain technology and advanced facilities and equipment investment, in order to improve the cold chain logistics service capability, to obtain rapid development.

2) Enterprises in addition to the focus on transportation and warehousing facilities, to pay attention to the development of cold chain logistics information system and the introduction. In order to occupy the market opportunities, maintain market position in the cold chain industry, strengthen the cold chain logistics management capabilities, enterprises must keep pace with the times, the construction of positive investment in information systems, including warehouse management system, transportation management system, EDI, GPS, whole temperature monitoring, through the network platform, to realize the cold chain logistics information real-time monitoring, realize the enterprise of fresh products from the source to the destination seamlessly.

3) Enterprise staff is to promote the core strength of the rapid development of enterprises, has an important effect on the performance of enterprises. Cold chain logistics enterprises shall regularly organize staff training, improve staff skills training, technical and management personnel for the cold chain logistics industry, enterprise leaders should correctly use the motivation effect to improve employee satisfaction, enhance the cohesion of the enterprise; in addition, the enterprise should pay attention to improve their ability to innovate, encourage innovation, including the innovation service mode, management mode and technology. In technological innovation, enterprises should adhere to the combination of introduction and self innovation, constantly stimulate their creative ability, the only way to form The core competitiveness of enterprises can effectively improve the level of enterprise performance, so that enterprises in the increasingly fierce competition in the market environment to achieve long-term development.

\section{REFERENCES}

[1] Dequan Yang, Jinying Pei, 2012. Performance evaluation of logistics enterprises based on super efficiency DEA-IAHP. Operations and management, (01): 189-194+255.

[2] Haolin Tong, 2014. Research on performance evaluation of Cold Chain Logistics Listed Companies in China. Logistics technology, (19): 337-339.

[3] Jiazhen Huo, Min Zhou, 2009. Logistics performance management. Tsinghua University press. Beijing, 10:226-229. 
[4] Jing Zhou, Jian Sun, 2015. Performance evaluation of cold chain logistics enterprises based on AHP-DEA model. Journal of social science, (05): 114-119.

[5] Weishu Xu, Xiangyu Fan, 2015. Performance evaluation of cold chain logistics of agricultural products based on Data
Envelopment Analysis. Logistics technology, (01): 152-155. [6] Yuping Huang, 2016. Performance evaluation of cold chain logistics enterprises of agricultural products. Modern marketing (published in late 2016,), (08): 98-99. 